\title{
Amplitude of visual suppression during the control of binocular rivalry
}

\author{
LEON C. LACK \\ School of Social Sciences, The Flinders University of South Australia, Bedford Park, South Australia 5042
}

\begin{abstract}
To investigate the precise mechanism of control of binocular rivalry, Ss were instructed to attend actively to whichever pattern was momentarily in the nonsuppression phase. Test stimuli were presented tachistoscopically for recognition in either phase of rivalry. Because the differential recognition between nonsuppressed and suppressed phases was no greater for an active condition than for a passive viewing condition, it was concluded that control is not mediated by varying the amplitude of the suppression effect. This result was consistent with control that is exercised by selecting the eye to receive a constant amplitude suppression. In addition, it was found that visual sensitivity of rivalry nonsuppression and nonrivalry were the same for the ocular dominant eye but different for the nondominant eye.
\end{abstract}

When the two eyes observe dissimilar patterns, an alternating phenomenal suppression known as binocular rivalry occurs between the patterns. Control of the phenomenal alternations has been recently reconfirmed; rivalry rate can be varied by instructional conditions (Meredith \& Meredith, 1962) and practice (Lack, 1969, 1970) through the operation of a central rather than a peripheral mechanism (Lack, 1971).

Fox and Check (1966a) found that phenomenal suppression during uncontrolled rivalry is correlated with impaired recognition of tachistoscopic stimuli. This objective effect of rivalry was applied by Collyer and Bevan (1970) to measure the control of rivalry. When Ss were given $3 \mathrm{sec}$ warning of which eye was to be stimulated, recognition improved about $10 \%$ above a no-warning condition. In another experiment, Ss were instructed to maintain the dominance of one eye for a complete session, resulting in a mean recognition difference between the instructed and noninstructed eyes of about $14 \%$. When control was not required but when Ss were allowed to trigger the target stimuli after the instructed eye passively entered the dominant phase, the recognition difference improved to about $16 \%$ (Collyer \& Bevan, 1970).

Control may have operated in either or both of the following ways to produce the results of Collyer and Bevan's experiments (1970): (1) a constant recognition difference between dominant and suppressed phases with the instructed eye in the dominant phase a majority of the time, or (2) variation of the amplitude of suppression.

The first mode of operation suggests that control is exerted by voluntarily selecting the eye to be made dominant. The extent to which Ss are successful in maintaining the instructed eye in the dominant rivalry phase would be reflected by the extent to which the recognition difference approached $16 \%$, which is apparently the maximum dominance-suppressed difference in Collyer and Bevan's study (1970). This model of control is consistent with the "subjective" measures of control based on rivalry rates (Meredith \& Meredith, 1962; Lack, 1969, 1970) or relative predominance (Breese, 1899; McDougall, 1903; Washburn \& Gillette, 1933) which operate by directing the phases of rivalry to the selected eye.

The operation of the second mode of dominance control would vary the difference in recognition performance between dominant and suppressed eyes. The difference would be increased when the instructed eye was, in fact, dominant and decreased if the noninstructed eye entered the dominance phase of rivalry. To illustrate this effect. Table 1 shows hypothetical recognition percentages for the two eyes and difference when the instructed eye is dominant (A) and when the noninstructed eye is dominant (B). In this case, the difference between rivalry phases would be $20 \%$ when the instructed eye is dominant and only $8 \%$ when the noninstructed eye is dominant. Even if the two eyes were in the dominance phase an equal amount of time, the average difference between the rivalry phases would be $14 \%$, which would be adequate to account for the Collyer and Bevan (1970) results. Thus. dominance control may be operating wholly or partly by varying the amplitude of the dominant-suppressed difference. The main purpose of this experiment is to test this possibility.

Table 1

Hypothetical Data

\begin{tabular}{|c|c|c|c|}
\hline & Eye & $\begin{array}{l}\text { Rivalry } \\
\text { Phase }\end{array}$ & $\begin{array}{l}\text { Recog- } \\
\text { nition } \\
\text { Percen- } \\
\text { tage }\end{array}$ \\
\hline A & $\begin{array}{l}\text { Instructed } \\
\text { Noninstructed }\end{array}$ & $\begin{array}{l}\text { Dominant } \\
\text { Suppressed }\end{array}$ & $\begin{array}{l}60 \\
40\end{array}$ \\
\hline & \multicolumn{2}{|c|}{ Difference } & 20 \\
\hline \multirow[t]{2}{*}{ B } & $\begin{array}{l}\text { Noninstructed } \\
\text { Instructed }\end{array}$ & $\begin{array}{l}\text { Dominant } \\
\text { Suppressed }\end{array}$ & $\begin{array}{l}60 \\
52\end{array}$ \\
\hline & \multicolumn{2}{|c|}{ Difference } & 8 \\
\hline
\end{tabular}


If the second mode of control is available. presumably it could be used to enhance the dominant-suppressed difference by instructing $S$ s to attend actively to whichever eye becomes dominant as the dominance phase naturally alternates between the eyes. Thus, a greater difference in recognition performance should result from this type of active attention condition than from the passive viewing condition.

A secondary purpose will be to reexamine the difference in recognition between the dominant phase of rivalry and a nonrivalry condition. Fox and Check (1966a) found a small but insignificant difference in recognition performance and concluded that the dominant phase of rivalry represented the same visual sensitivity as the nonrivalry condition. On the other hand. Collyer and Bevan (1970) found the rivalry dominant phase to be about $15 \%-17 \%$ less than nonrivalry recognition. Although they did not state the significance level of this difference, they concluded that the visual sensitivity during the dominant phase of rivalry was less than that of monocular nonrivalry. Hence, this discrepancy needs to be resolved.

\section{METHOD}

\section{Subjects}

Six males and six females from an earlier experiment (Lack, 1970 ) volunteered to serve as Ss. They were all from a group of 15 Ss who had received a total of $60 \mathrm{~min}$ of spaced practice of "slow-rate" and "rapid-rate" rivalry instructions with knowledge of results. Thus. the Ss were well practiced in the control of rivalry rate. All had uncorrected normal vision and were naive to the purpose of the present experiment.

\section{Stimuli}

Black squares. 1 deg $20 \mathrm{~min}$ in visual extent, were drawn on white backgrounds in the left- and right-eye fields and coincided in the binocular condition to serve as fusion stimuli. The rivalry stimuli were similar to those used by Fox and Check (1966a), consisting of diagonal lines filling the fusion squares. The right rivaly stimulus consisted of five parallel lines at 45 deg to vertical: the left rivalry stimulus was the same, but rotated $90 \mathrm{deg}$. All the black lines were $10 \mathrm{~min}$ of visual angle thick. The target stimuli were four letter forms (A, S, T, C) typed in capital letters on white stimulus cards. Mounted in the second field of a tachistoscope, the letter forms were visually centered in either the left or right fusion squares and subtended $25 \mathrm{~min}$ of visual field. about one-third the size of the rivalry stimuli.

\section{Apparatus}

The basic apparatus consisted of a modified Stereo-king Model HN-44 stereoscope mounted to the viewing hole of the modified Cambridge two-field tachistoscope. Although accommodation blurring and pupillary changes do not contribute significantly to control of rivalry (Lack, 1971). artificial pupils are useful for minimizing head movement. Artificial pupils $(2.8 \mathrm{~mm})$, adjusted to the interocular distance of any S. Were mounted in front of the lenses of the stereoscope. and a chinrest was adjusted to provide a stable head position.

The tachistoscope was modified to allow a brief superimposition of target stimuli on fusion or rivalry stimuli. Before and after target stimulus exposure. the luminance of the black lines of the fusion squares and rivalr stimuli. as measured with an S.E.I. spot photometer, was $0.016 \mathrm{fL}$. The white background was a uniform $0.4 \mathrm{fL}$. During the target stimulus exposure, the luminance of the black lines and black letter forms was $0.1 \mathrm{fL}$ and the white background was a uniform $0.5 \mathrm{fL}$.

Two telegraph keys were used by Ss to indicate phenomenal rivalry alternations or to simulate hypothetical rivalry. The telegraph keys operated a cumulative timer and digital counter and enabled a measure of ocular dominance and rivalry rate. $A$ $50-\mathrm{Hz}$ buzzer of $0.2 \mathrm{sec}$ duration was used as a warning signal preceding the presentation of target stimuli by $0.5 \mathrm{sec}$.

\section{Procedure}

The experiment was divided into four test sessions held on 4 successive days for all $S$ s. The first was a preliminary session for testing ocular dominance and fixing a tachistoscopic duration for each S. Ocular dominance was measured using the Miles A-B-C Sighting Test (Miles, 1929), in addition to two measures using binocular rivalry - one in which Ss passively viewed rivalry during a 60-sec period and a second in which Ss followed "slow-rate" and "rapid-rate" instructions each during four 30-sec periods. From all three tests, a dichotomous left-right eve dominance classification could be made. The two rivalry measures provided additional information of the degree of right or left eve dominance.

To establish a suitable exposure duration of test stimuli, a descending staircase method of $10-\mathrm{msec}$ steps was started at $100 \mathrm{msec}$. With letter forms presented to the dominant eye in the nonrivaly condition, most $S$ s produced a suitable recognition performance of about $60 \%$ with exposure durations of 40 or 50 msec.

Following the preliminary session, the three conditions of nonrivalry, passive rivalry, and active rivalry were presented in balanced order on three successive test sessions. In the nonrivalry condition. the diagonal rivalry lines were removed from one fusion square. Since in the binocular condition the remaining "rivalry" stimulus was continuously dominant, target stimuli presented to that eye were labeled "nonsuppressed" phase trials and target stimuli to the blank field eye were labeled "suppressed." Both the dominant and nondominant eyes viewed the rivalry stimulus or "nonsuppressed" phase an equal number of trials in the nonrivalry condition. To equate possible detrimental effects of key-tapping. Ss were instructed to simulate rivalry in the nonrivalry condition by alternately tapping the telegraph keys.

In the passive and active viewing conditions. Ss tapped the left and right telegraph keys to indicate alternations of the nonsuppressed (dominant) phase of rivalry to the left and right eyes. respectively. In the passive condition. Ss were instructed to watch in a passive manner and to avoid actively influencing the rivalry. In the active condition, Ss were instructed to attend to whichever pattern was momentarily nonsuppressed to make it as completely dominant as possible. When it became difficult to hold one pattern exclusively. Ss were to make the change of nonsuppression phase to the other pattern as dichotomous as possible.

Each $S$ received 80 target stimulus exposures in each condition with the four letter-form stimuli balanced between dominant and nondominant eyes in both the nonsuppressed and suppressed phases of rivalry. No information about target stimulus presentation was given before a trial and no knowledge of results was given following a trial. Ss were told that target stimuli would be presented to either eye in either phase of rivalry with an equal probability. The 80 trials were run in four blocks of 20 each. requiring about $6 \mathrm{~min}$ with 2 -min rests between blocks.

The Ss were instructed to fixate the center of the rivalry stimuli and to be as accurate as possible in indicating rivalry alternations. Following two to five alternations of rivaly or simulated rivalry. the $\mathrm{E}$ presented the waming buzzer $0.3 \mathrm{sec}$ after the first appropriate key-tap, as determined by the 
Fig. 1. Mean percentage recognition scores for 12 Ss in three viewing conditions for both the dominant (D) and nondominant (ND) eye under both the suppressed (S) and nonsuppressed (NS) rivalry phases.

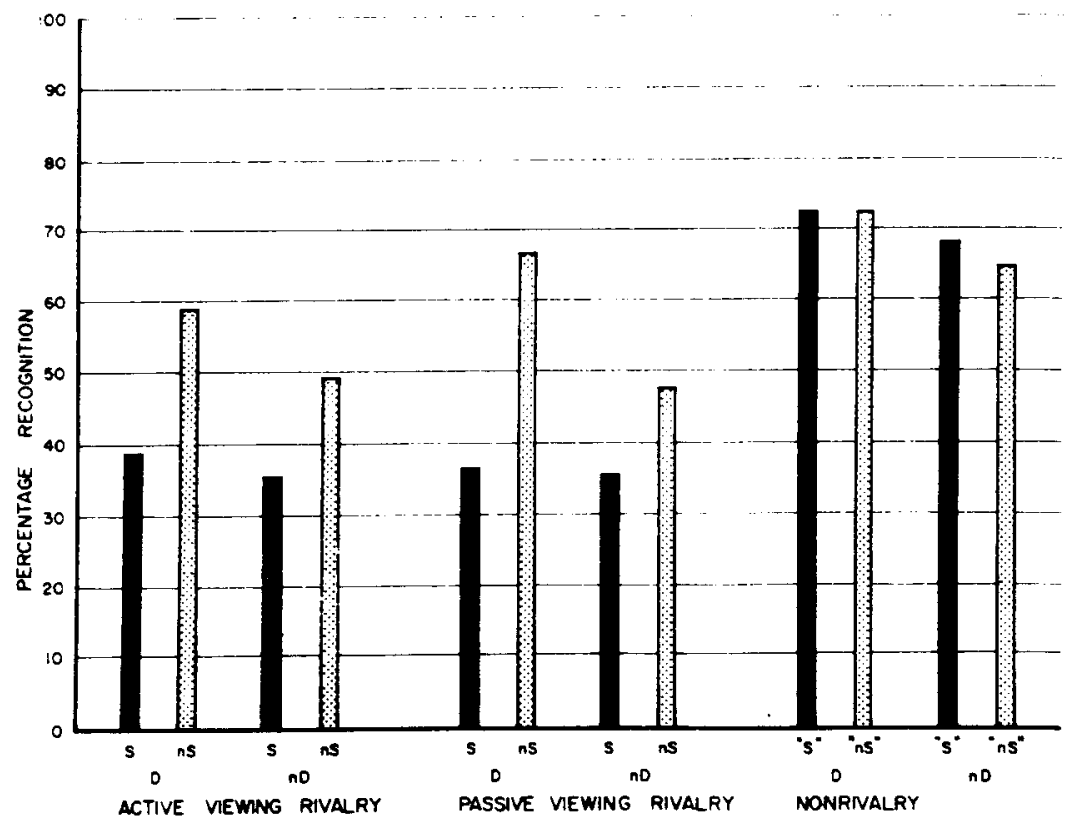

presentation schedule. The target stimulus was then triggered approximately $0.5 \mathrm{sec}$ following the warning stimulus. The S immediately responded in a forced-choice task with one of the letter forms. S then had $10-15 \mathrm{sec}$ of rest before resuming the instructional conditions and key-tapping.

\section{RESULTS AND DISCUSSION}

In the dichotomous classification of ocular dominance, the two rivalry tests agreed in all $12 \mathrm{Ss}$. With the inclusion of the more precise dominance information, the Pearson correlation of the two tests was significant $(\mathrm{r}=+0.746, \mathrm{df}=10, \mathrm{p}<.005)$. On the other hand, the Miles Sighting Test and rivalry tests agreed with only 9 Ss, thus failing to reach significant correspondence using the chi-square test $\left(\chi^{2}=3.09, \mathrm{df}=\right.$

Table 2

Analysis of Variance of Recognition Scores Including the Main Effects of Rivaly Phase (P), Eye Dominance (D), Viewing Condition (C), and Subjects (S)

\begin{tabular}{lrrrr}
\hline \multicolumn{1}{c}{ Source } & df & $\begin{array}{c}\text { Mean } \\
\text { Squares }\end{array}$ & \multicolumn{1}{c}{ F } & p \\
\hline Rivalry Phase (P) & 1 & 380.01 & 19.83 & $<.005$ \\
Eye Dominance (D) & 1 & 55.51 & 1.13 & n.s. \\
Viewing Condition (C) & 1 & 3.01 & 0.40 & n.s. \\
Subjects (S) & 11 & 42.58 & & \\
P by D & 1 & 29.26 & 6.55 & $<.05$ \\
P by C & 1 & 6.51 & 0.78 & n.s. \\
P by S & 11 & 19.17 & & \\
D by C & 1 & 1.26 & 0.49 & n.s. \\
D by S & 11 & 42.36 & & \\
C by S & 11 & 7.59 & & \\
P by D by C & 1 & 5.51 & 1.08 & n.s. \\
P by D by S & 11 & 4.47 & & \\
P by C by S & 11 & 8.35 & & \\
D by C by S & 11 & 2.60 & & \\
P by D by C by S & 11 & 5.12 & & \\
\hline
\end{tabular}

$1, p>.05)$. This is consistent with earlier findings of the large amount of disparity between these measures (Washburn, Faison, \& Scott, 1934). Hence, for the following data analysis, ocular dominance will be that derived from the rivalry tests.

Figure 1 shows the mean percentage recognition scores for the three viewing conditions, each separated into dominant and nondominant eye and each eye separated into the suppressed and nonsuppressed phases. The main hypothesis of the experiment was that the nonsuppressed-suppressed difference (NS-S) would be greater in the active than in the passive condition. The results of a four-way analysis of variance of recognition scores. including the main effects of conditions (active and passive), rivalry phases (nonsuppressed and suppressed), and eye dominance (dominant and nondominant), are shown in Table 2. The appropriate error term in each case is Ss' interaction. The only significant main effect is rivalry phase: rivalry suppression produces significantly lower $(p<.005)$ recognition than does nonsuppression. The test of the hypothesis, the Phase by Condition interaction, shows that the (NS-S) difference is not greater in the active than in the passive condition $(F=0.78)$. Therefore, the instruction to attend actively to the nonsuppressed rivalry patterns did not result in an increased difference in recognition scores between the nonsuppressed and suppressed phases of rivalry.

These results would have been expected if the Ss lacked control and were unable to follow instructions. However, the measures of control of rivalry rate ranged from $33.3 \%$ to $71.4 \%$ with a mean of $50.4 \%$, which was above the mean for unpracticed Ss (Lack, 1970). From the main hypothesis it would also be predicted that Ss with greater control should produce greater (NS-S) 
differences in the active condition. The Pearson correlation was low and did not approach a significant level $(r=+0.28$, df $=12, p>.20)$. Thus, neither instructional conditions nor individuals' degree of rivalry control are related to the magnitude of the (NS-S) difference.

From these results it is possible to eliminate the second of the two previously suggested models. Control does not seem to result in a greater amplitude of the suppression effect. This is consistent with the findings that rivalry suppression produces a constant $\log$ unit increase of threshold (Fox \& Check, 1968; Wales \& Fox, 1970) and with the finding that the inhibitory effect is constant throughout the duration of the suppression phase (Check, 1969).

The investigation of the nonrivalry-nonsuppressed difference implicates the factor of eye dominance. In the passive condition, the nonsuppressed mean is not less than the nonrivalry condition for the dominant eye $(t=$ 0.99 , df $=11, p>.20)$, but for the nondominant eye, this difference is significant $(t=3.14, d f=11, p<.01)$. Because the four suppressed phase means of the active and passive conditions are all similar and significantly ( $p$ $=.01$ ) above chance level ( $25 \%$ ), the (NS-S) values of the dominant eye are greater than those of the nondominant eye as indicated by the significant interaction $(F=6.55$, $\mathrm{df}=1 / 11, \mathrm{p}<.05)$ between rivalry phase and eye dominance as shown in Table 2. Interestingly, if eye dominance is assigned according to the Miles test, there is no difference between the "dominant" and "nondominant" eye $(t=0.57, \mathrm{df}=11, \mathrm{p}>.20)$ in the magnitude of the (NS-S) difference. Therefore, when eye dominance is determined by a rivalry test, the nonsuppressed phase appears to be similar to the nonrivalry condition in the dominant eye but nonsuppression is less than nonrivalry in the nondominant eye.

Collyer and Bevan (1970) analyzed their results without respect to eye dominance, thus overlooking possible differences between eyes. This may be one explanation of the discrepancy between their conclusion and that of Fox and Check (1966a) with respect to the nonrivalry-nonsuppressed difference.

Another source of discrepancy may arise from the difference in nonrivalry conditions. Fox and Check (1966a) removed the rivalry lines from one field, resulting in what may be termed a binocular nonrivalry condition. Collyer and Bevan (1970) darkened one field entirely to produce a monocular nonrivalry condition. It may be argued that binocular nonrivalry contains some suppression and results in inferior recognition as compared with the monocular condition. This would explain the greater nonrivalry-nonsuppression difference in the Collyer and Bevan study (1970). This argument would suggest a decreased recognition performance for the blank or "suppressed" field in the binocular nonrivalry condition. However, from Fig. 1 it is clear that "suppressed" is not less than "nonsuppressed" recognition. This result, together with the finding that binocular fusion is free from inhibitory effects (Fox \& Check, 1966b), suggests that binocular nonrivalry does not contain rivalry suppression and therefore is probably not different from monocular nonrivalry.

A more likely source of discrepancy arises from the difference in rivalry stimuli. The present study used stimuli similar to those used by Fox and Check (1966a). Collyer and Bevan (1970) used more complicated rivalry stimuli, each consisting of 40 parallel thin line segments. The rivalry from these stimuli may well have been less unitary than that experienced with simple stimuli. Thus, the nonsuppressed phase in Collyer and Bevan's study (1970) often may have contained areas of suppression resulting in reduced recognition compared with nonrivalry.

Because of differences in rivalry stimuli and because Collyer and Bevan (1970) did not investigate the effect of eye dominance, their conclusion that the nonsuppressed phase was of lower sensitivity than nonrivalry may not be true in general. The present experiment found a reduced sensitivity of the nonsuppressed phase for the nondominant eye but not for the dominant eye.

If rivalry is taken as a paradigm of attention, as it was by earlier investigators (Helmholtz, 1873; James, 1891; McDougall, 1903), then the finding that control does not affect the amplitude of suppression may have implications for other modes of selective attention. Control of attention in a dichotic listening task results in differential signal detectability (Broadbent \& Gregory, 1963; Moray \& O'Brien, 1967; Treisman \& Geffen, 1967). However, it is unclear from these findings whether reduced detectability in the unwanted ear resulted from a continuous suppression which may have varied in amplitude or resulted from a constant suppression amplitude that occasionally alternated between ears. With respect to binocular rivalry, control is effected by selecting which eye will be in the nonsuppression or suppression phase. Alternations to the unwanted eye are usually unavoidable, but because the selected eye is in nonsuppression a majority of the time, differential recognition performance is obtained from dominance control. If the effects of dominance control in binocular rivalry were true for attention in general, it would suggest that selective attention to one sensory channel results a majority of the time in a fixed amplitude suppression of nonselected channels.

\section{REFERENCES}

Breese, B. B. On inhibition. Psychological Monographs, 1899, 3, 1-65.

Broadbent, D. E., \& Gregory, M. Division of attention and the decision theory of signal detection. Proceedings of the Royal Society of London, Series B, 1963, 158, 222-231.

Check, R. J. An analysis of the temporal course of suppression during binocular rivalry. Dissertation Abstracts, 1969, 29. 3502-b. 
Collyer, S. C.. \& Bevan. W. Objective measurement of dominance control in binocular rivalry. Perception \& Psychophysics. $1970,8,437-439$.

Fox, R., \& Check. R. Forced-choice form recognition during binocular rivaly. Psychonomic Science. 1966a. 6, 471-472.

Fox, R., \& Check. R. Binocular fusion: A test of the suppression theory. Perception \& Psychophysics. 1966b. 1, 331-334.

Fox, R., \& Check. R. Detection of motion during binocular rivalry suppression. Journal of Experimental Psychology, 1968, 78, 388-395.

Helmholtz. H. von Popular lectures on scientific subjects. (Trans. E. Atkinson) London: Longmans, Green, 1873.

James, W. The principles of psichology. London: MacMillan. 1891. (Republished-New York: Dover, 1962.)

Lack, L. C. The effect of practice on binocular rivalry control. Perception \& Psychophysics, 1969, 6, 397-400.

Lack, L. C. Effects of knowledge of results and spacing of practice trials in training of control of binocular rivalry. Perceptual \& Motor Skills, 1970, 31. 827-830.

Lack, L. C. The role of accommodation in the control of binocular rivalry. Perception \& Psychophysics, 1971, 10 , 38-42.

McDougall, $W$. The physiological factors of the attention-process (III). Mind, 1903, 12, 473-488.

Meredith, G. M., \& Meredith, C. G. W. Effect of instructional conditions on rate of binocular rivalry. Perceptual \& Motor
Skills. 1962, 15, 655-664.

Miles, W. R. Ocular dominance demonstrated by unconscious sighting. Journal of Experimental Psychology. 1929, 12, $113-126$.

Moray, N., \& O'Brien. T. Signal-detection theory applied to selective listening. Journal of the Acoustical Society of America. 1967, 42, 765-772.

Treisman, M., \& Geffen, G. Selective attention: Perception or response? Quarterly Journal of Experimental Psychology, 1967, 19, 1-17.

Wales, R., \& Fox. R. Increment detection thresholds during binocular rivalry suppression. Perception \& Psychophysics. $1970,8,90-94$.

Washburn, M. F., Faison, C., \& Scott. R. A comparison between the Miles A-B-C method and retinal rivalry as tests of ocular dominance. American Journal of Psychology: 1934, 46. 633-636.

Washburn, M. R.. \& Gillette. A. Studies from the Psychological Laboratory of Vassar College: LXII. Motor factors in voluntary control of cube perspective fluctuations and retinal rivalry fluctuations. American Journal of Psychology. 1933, 45. 315-319.

(Received for publication April 17, 1972; accepted November 20,1972 .) 